\title{
EXTUBACIÓN INMEDIATA EN TRASPLANTE HEPÁTICO
}

Rinaldi Leonardo Iván ${ }^{1}$, Despuy Juan Pedro ${ }^{1}$, Siri Juan ${ }^{1}$

1 Asociación anestesia, analgesia y reanimación de Córdoba. Argentina.

Introducción: Hasta hace algunos años, todos los pacientes sometidos a trasplante hepático eran trasladados en el postoperatorio inmediato a la Unidad de Terapia Intensiva (UTI) bajo Asistencia respiratoria Mecánica (ARM) para iniciar su recuperación. Sin embargo, en los últimos años, no sólo la técnica quirúrgica, sino también el manejo anestésico de estos pacientes ha mejorado, y en un número cada vez mayor de Centros Hospitalarios alrededor del mundo ha comenzado la práctica de extubación inmediata post trasplante hepático.

Objetivo General: Analizar el impacto de la extubación inmediata postquirúrgica en pacientes sometidos a Trasplante hepático, determinar los potenciales riesgo, y la relación costo-beneficio, en un Centro Hospitalario en Argentina.

Material y Métodos: Utilizando el sistema electrónico del Hospital Privado (HP) se realizó una búsqueda retrospectiva de la evolución clínica de 127 pacientes que fueron sometidos a Trasplante Hepático $(\mathrm{TH})$ entre enero de 2005 y julio de 2015. Se definió como "inmediata" a toda aquella extubación realizada en la sala de operaciones en un tiempo menor a 1 hora. Se establecieron los criterios específicos utilizados en la Institución para definir a los pacientes aptos para la extubación inmediata.

Resultados: Se realizo análisis de subgrupos dentro de los datos recolectados, donde se com- pararon diferentes variables entre aquellos pacientes extubados inmediatamente, y aquellos con extubación tardía. Aquellos pacientes con extubación inmediata presentaron un MELD de 19 (DS $\pm 4,2$ ), una media de 2 UGR transfundidas durante el procedimiento ( $\mathrm{DS} \pm 1,2$ ), permanecieron una media de 2,9 días en UTI (DS \pm 1.8 ), y presentaron menor prevalencia de $\mathrm{Fa}$ lla renal $(28 \%)$. Aquellos con extubación tardía presentaron MELD 23,4 (DS $\pm 10,1)$, una media de 5,5 UGR transfundidas durante el procedimiento ( $\mathrm{DS} \pm 3,3$ ), permanecieron 10,2 días en UTI (DS $\pm 12,1)$ y presentaron mayor prevalencia de falla renal $(68,4 \%)$. No se registró ninguna re-intubación en los pacientes extubados en quirófano.

Conclusiones: Además de los beneficios clínicos evidentes en aquellos pacientes extubados de inmediato (Menor incidencia de re-intervenciones, menos días de UTI, menor prevalencia de fallo renal), ésta modalidad permite un ahorro económico, ya que los costos por día de internación en UTI oscilan desde $\$ 533,33$ dólares (pacientes sin ARM) vs $\$ 637,20$ dólares (con ARM) y una reorganización y optimización de recursos Hospitalarios. La extubación inmediata parece ser segura y rentable, sin embargo, son necesarios estudios con mayor número de pacientes $\mathrm{y}$ muestras homogéneas para establecer conclusiones definitivas. 